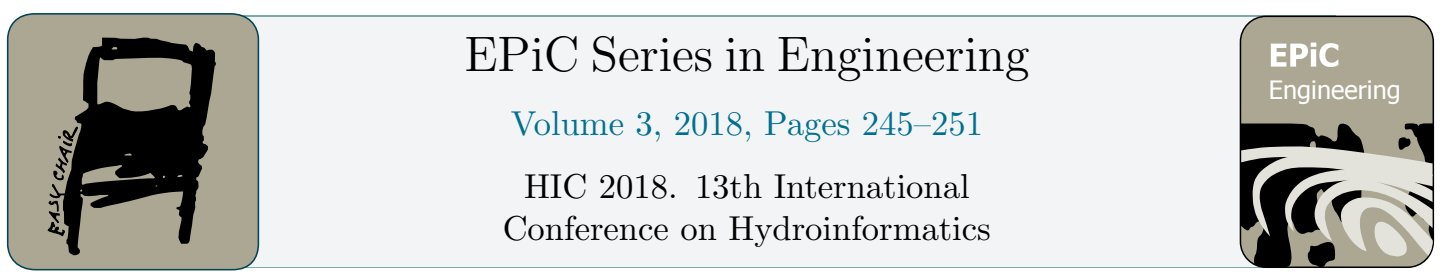

\title{
Hydrological and erosion modelling of the Brahmaputra basin using global datasets
}

\author{
Biswa Bhattacharya ${ }^{1}$, Crystal Conway ${ }^{2}$, Dimitri Solomatine ${ }^{1}$, Ilyas Masih ${ }^{1}$, \\ Joanne Craven ${ }^{1}$, Liton Chandra Mazumder ${ }^{2}$, Maurizio Mazzoleni ${ }^{1}$, \\ Reyne Ugay ${ }^{2}$, Schalk Jan van Andel ${ }^{1}$ and Shreedeepy Shrestha ${ }^{2}$ \\ ${ }^{1}$ IHE Delft Institute for Water Education, Westvest 7, 2601 DA Delft, \\ The Netherlands. \\ ${ }^{2}$ Former MSc student, IHE Delft Institute for Water Education.
}

Corresponding author: B.Bhattacharya@un-ihe.org

\begin{abstract}
Limited hydro-meteorological and sediment data of the Brahmaputra basin is available and as a result, water resources management of the basin is a challenge. Advances in remote sensing provide opportunities to access alternative data, which can be used in characterising the basin. We present hydrological and erosion models of the basin developed using remotely sensed data. In particular a hydrological model using HEC-HMS was developed using the elevation data from the Shuttle Radar Topographic Mission (SRTM). The hydrology of the basin was simulated using rainfall data from the Tropical Rainfall Measuring Mission (TRMM). Evapotranspiration, temperature, soil and landuse were collected from remotely sensed data sources. The uncertainty in the model parameters due to the uncertainty of the downstream rating curve used in the calibration of the model was estimated. Another hydrological model using SWAT was also developed to simulate the erosion pattern in the basin. A hydraulic model of the Brahmaputra River was developed using HEC-RAS. Simulated flood maps were compared with satellite imageries. A conclusion was reached that the models are able to simulate the hydrological and hydraulic processes in the basin with reasonable accuracy. Due to the lack of data the erosion model could not be validated.
\end{abstract}

Keywords: Brahmaputra, flood map, hydraulic modelling, hydrological modelling, remote sensing, sediment. 
Hydrological and Erosion Modelling of the Brahmaputra Basin Using Global ...B. Bhattacharya et al.

\section{Introduction}

The lack of hydro-meteorological data for a large number of catchments around the world is a major constraint to implementing efficient water resources management there. One of the possible solutions to the scarcity of rainfall data or transboundary data issues seemed to be in making use of the variety of satellite based estimates and meteorological model products for rainfall. Such rainfall data, together with remotely sensed data of evapotranspiration, temperature, soil and landuse may be used in simulation models for understanding the system dynamics. See, for example, AriasHidalgo et al. [1] for further details. In this paper we address the possibility of modelling hydrological, hydraulic and erosion processes using remotely sensed data. Brahmaputra is a large basin with a lot of potential for socio-economic development. The basin is largely ungauged. The basin is transboundary and data sharing issues are present. Knowledge about the spatial and temporal variation of rainfall is absolutely important in hydrological studies for analysing catchment characteristics. Although there are very few raingauges in the basin there is a large variety of satellite-based rainfall products such as those from TRMM [2]. The availability of free global datasets provides a good basis for hydrological modelling in data-scarce catchments. These global datasets are products of remote sensing and compilation of regional records. In this paper the results from simulation modelling of the Brahmaputra basin using global datasets are presented.

\section{Study area}

Brahmaputra River originates from the great glacier mass of Chema-Yung-Dung in the Kailas range of southern Tibet at an elevation of $5300 \mathrm{~m}$ and traverses $3410 \mathrm{~km}$ flowing through China $(1995 \mathrm{~km})$, India $(983 \mathrm{~km})$ and Bangladesh $(432 \mathrm{~km})$ before emptying into the Bay of Bengal (Fig. 1). The basin has an area of around $556365 \mathrm{~km} 2$ spreading over China $(\sim 50 \%)$, Bhutan $(\sim 8 \%)$, India $(\sim 34 \%)$ and Bangladesh $(\sim 8 \%)$. The basin consists of quite diverse environments such as the cold dry plateau of Tibet, rain-drenched Himalayan slopes, landlocked alluvial plains of Assam and the vast deltaic lowlands of Bangladesh. The Brahmaputra basin, excluding the Tibetan portion, forms an integral part of the southeast Asian monsoon region with a mean annual rainfall of $2300 \mathrm{~mm}$. Distribution of rainfall over the basin varies ranging from $1200 \mathrm{~mm}$ in parts of Nagaland to over $6000 \mathrm{~mm}$ on the southern slopes of the Himalaya. Monsoon rains from June to September account for $60-70 \%$ of the annual rainfall in the basin, while the pre-monsoon season from March through May produces $20-25 \%$ of the annual rainfall. Snowfall is experienced in the basin in areas with

elevations of $1500 \mathrm{~m}$ above sea level (ASL) and above. 
Hydrological and Erosion Modelling of the Brahmaputra Basin Using Global ...B. Bhattacharya et al.

\section{Data and methods}

\subsection{Data}

The digital elevation model (DEM) of the basin was developed using the data from SRTM [4]. This data has a resolution of $90 \mathrm{~m} \times 90 \mathrm{~m}$, which is coarse but was considered sufficient for the large basin, wide river and expanded floodplains. The SRTM data was further used in delineating the river and its cross-sections. The TRMM data (3B42, version 7) has been used in the hydrological simulation. Other satellite based rainfall data may be used in the future. This data is of daily resolution and is available for the period 1998 to 2015. Daily temperature data was needed to simulate the snowmelt and was obtained from Atmospheric Infrared Sounder (AIRS) available at NASA's Earth Data portal (http://giovanni.sci.gsfc.nasa.gov/giovanni). The monthly average evapotranspiration data from the GeoNetwork of the Food and Agricultural Organisation (FAO) was used. The Harmonized World Soil Database (version 1.2) from FAO was used for the soil data. The landuse data was based on the Globcover dataset of the European Space Agency (ESA). The rating curve and the daily time series data of stage at the outlet of the basin (Bahadurabad) was used for the calibration of the hydrological model.

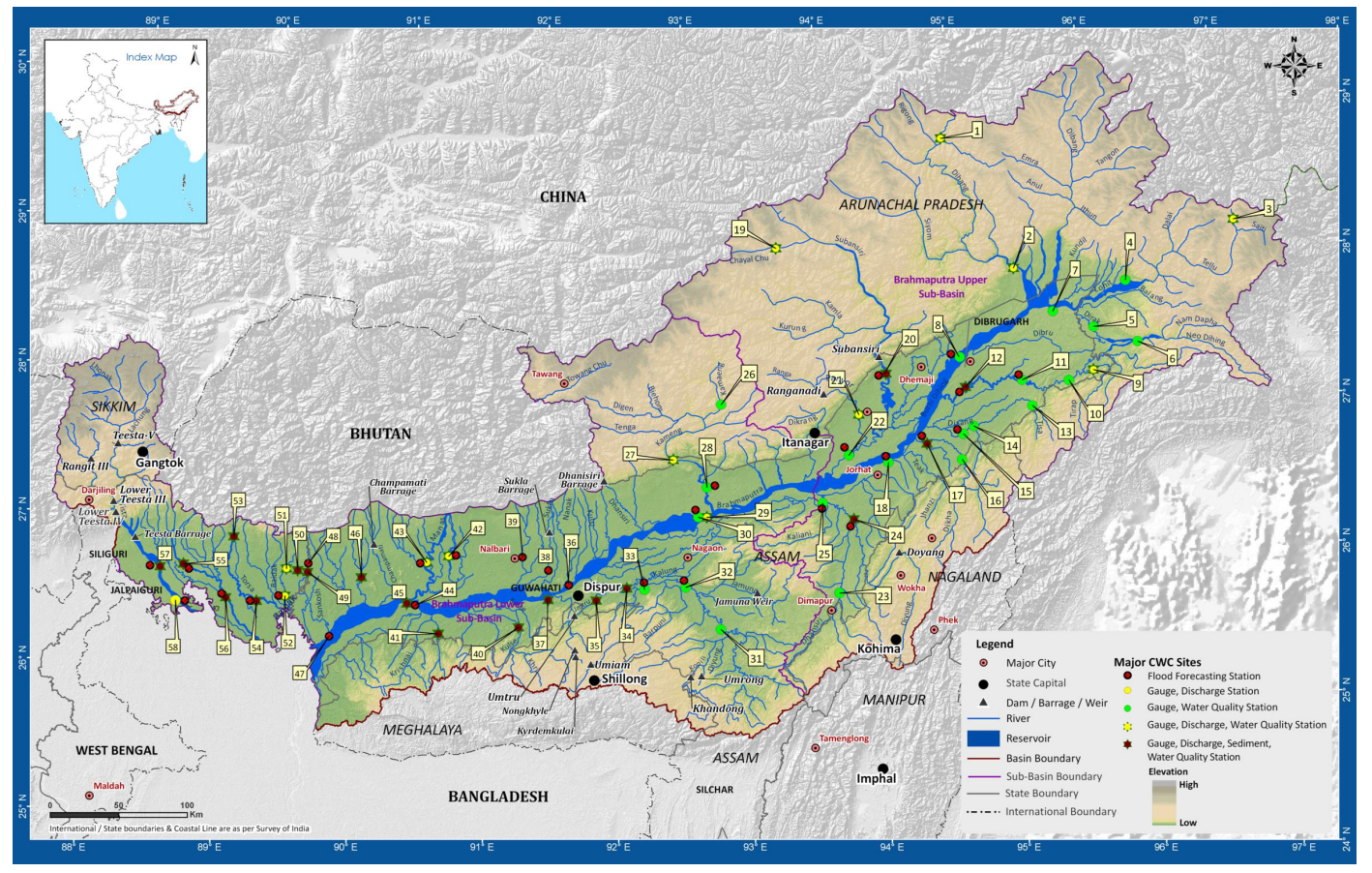

Fig. 1. The Indian part of the Brahmaputra basin (from [3]). 
Hydrological and Erosion Modelling of the Brahmaputra Basin Using Global ...B. Bhattacharya et al.

\section{Data and methods}

\subsection{Data}

The digital elevation model (DEM) of the basin was developed using the data from SRTM [4]. This data has a resolution of $90 \mathrm{~m} \times 90 \mathrm{~m}$, which is coarse but was considered sufficient for the large basin, wide river and expanded floodplains. The SRTM data was further used in delineating the river and its cross-sections. The TRMM data (3B42, version 7) has been used in the hydrological simulation. Other satellite based rainfall data may be used in the future. This data is of daily resolution and is available for the period 1998 to 2015. Daily temperature data was needed to simulate the snowmelt and was obtained from Atmospheric Infrared Sounder (AIRS) available at NASA's Earth Data portal (http://giovanni.sci.gsfc.nasa.gov/giovanni). The monthly average evapotranspiration data from the GeoNetwork of the Food and Agricultural Organisation (FAO) was used. The Harmonized World Soil Database (version 1.2) from FAO was used for the soil data. The landuse data was based on the Globcover dataset of the European Space Agency (ESA). The rating curve and the daily time series data of stage at the outlet of the basin (Bahadurabad) was used for the calibration of the hydrological model.

\subsection{Methodology}

A semi-distributed hydrological model using HEC-HMS was developed using the SRTM DEM with the outlet at Bahadurabad. A Soil Moisture Accounting model was used for the loss, Clark Unit Hydrograph was used for the runoff, Linear Reservoir was used for the baseflow and Temperature Index method was used for the snowmelt. The model was calibrated for the period 2005-2014 and validated for the period 20002004 at a daily time step using the TRMM data and other data mentioned above. Discharge values estimated from the rating curve at Bahadurabad, which was used in calibrating the model, showed considerable differences with the sporadically available measured discharge data. The mean $(\mu)$ and standard deviation $(\sigma)$ of the measured discharge values were computed and 50 rating curves were sampled from the range $\mu+3 \sigma$ to $\mu-3 \sigma$. The choice of the range ensures that a sampled rating curve lies with $99 \%$ likelihood within the possible discharge values. The hydrological model was calibrated 50 times each time using one particular rating curve, thereby leading to 50 sets of parameter values. A hydraulic model based on HEC-RAS was developed for the last $500 \mathrm{~km}$ of the river. The model was simulated 50 times with 50 sets of runoff data from the HMS model. The SWAT model was developed using the same DEM and was simulated for the same period to provide erosion rates.

\section{Results and discussion}

The simulated hydrographs from fifty simulation runs were compared with the measured discharge at the outlet of the basin (Fig. 2) and it can be seen that the model has large uncertainties, particularly for the high peaks. The root mean square error 
(RMSE) was 7702 and $7989 \mathrm{~m} 3 / \mathrm{s}$ for the calibration and validation period respectively whereas the average discharge was 20870 and $22734 \mathrm{~m} 3 / \mathrm{s}$. The Nash-Sutcliffe coefficient was 0.83 and 0.82 for the calibration and validation period. Fig. 2 also shows the comparison of the discharge simulated by the hydraulic model with the measured discharge. The simulated flood map for a flood event on 29 June 2012 was compared with the satellite image based flood map (from the Dartmouth Flood Observatory) and a reasonably good match was observed (Fig. 3). Each pixel of the simulated flood map was compared with the satellite based flood map and the number of pixels with correct positive rejection, hit, miss and false alarm was counted. The probability of detection, which is a ratio of the number of pixels with correct positive rejection and the sum of the number of pixels with correct positive rejection and the number of pixels with miss, was found to be 0.71 .
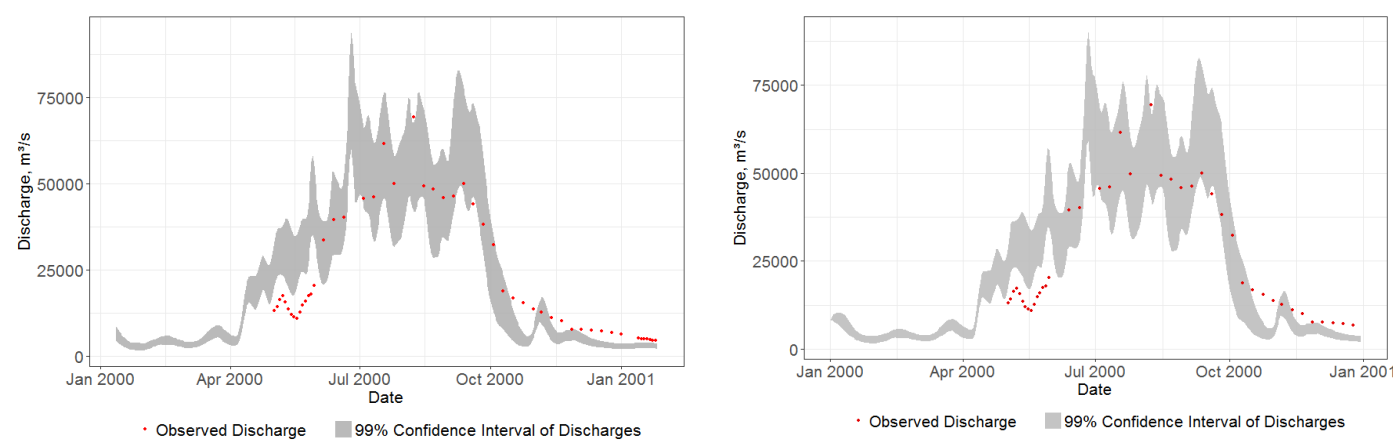

Fig. 2. Validation results of the hydrological results (left) and the hydraulic model (right) at Bahadurabad location.
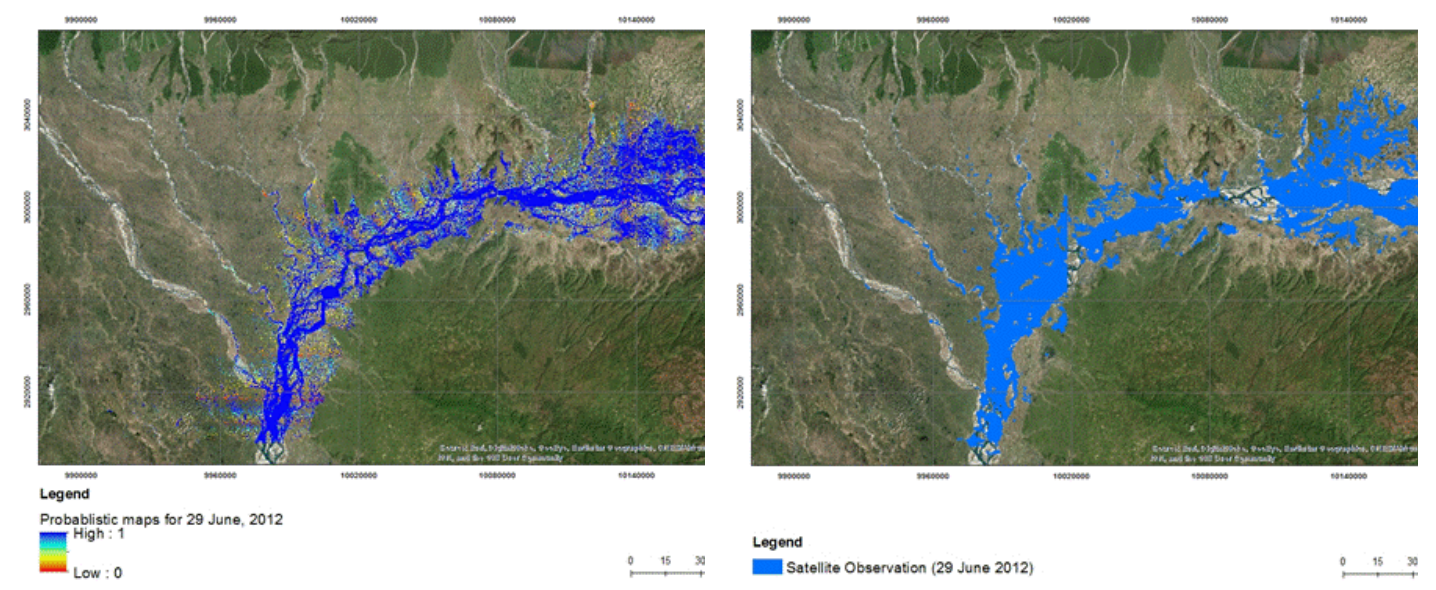

Fig. 3. Comparison of simulated inundation map (left) with the satellite image (right) for a flood event on 29 June 2012. 
The SWAT model was simulated for the period 2000-2004 and based on the simulated results the predicted average annual sediment yield of the entire basin was found to be 78.9 tonnes/ha/yr. The erosion map (Fig. 4) shows a high variation in the annual average sediment yield across different sub-basins. About half of the total basin area, which mostly is in the western part in the Tibetan plateau, has annaul average sediment yield of $0-50$ tonnes/ha/yr. About $18.5 \%$ of the basin area showed annual sediment yield of 50-100 tonnes/ha/year. Some areas in the north and the east of the basin showed annual sediment yield of 100-500 tonnes/ha/year. Because of lack of data we could not simulate the sediment yield of the very north eastern part of the basin. Due to the lack of data the model results could not be validated. Establishing a causal relationship between the sediment yield and hydrological process was not possible and the reasons behind the very high sediment yield at some areas of the basin remained unknown. The sub basins with high erosion typically have lithosols as their soil type, higher slopes, varied land cover and precipitation ranging from $500-2500 \mathrm{~mm} / \mathrm{yr}$ but so did other sub-basins with lower sediment yield. Hence, specific driving factors for variation in the sediment yield could not be clearly stated.

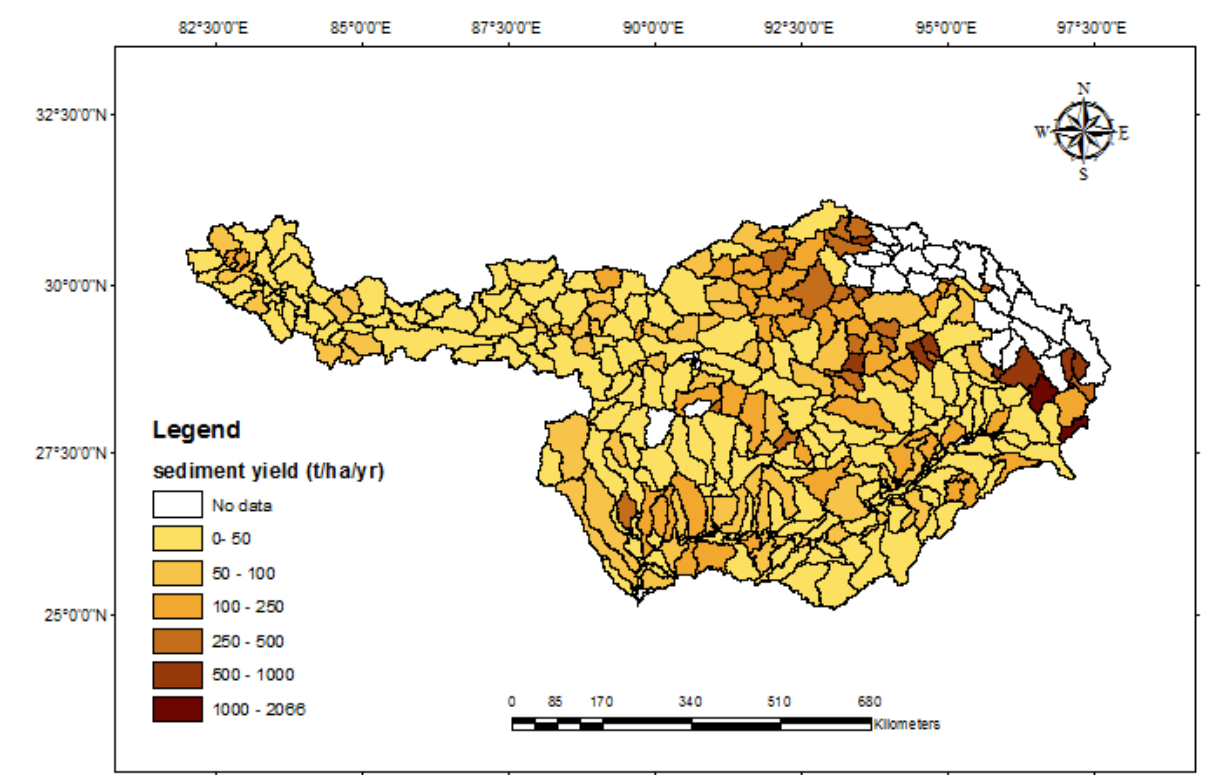

Fig. 4. Average erosion rates of different sub-basins of the Brahmaputra basin.

Singh [5] traced the sources of sediment in Brahmaputra using the $\mathrm{Sr}$ and $\mathrm{Nd}$ isotopes of the sediment collected between Pasighat and Dhrubi (lower part of the basin) and concluded that Eastern Syntaxix zone (the big bend around Namcha Baruwa) in the basin is the primary contributor of sediments. However, our model results do not show 
Hydrological and Erosion Modelling of the Brahmaputra Basin Using Global ...B. Bhattacharya et al.

very high erosion rates in this area. Singh [5] further argued that Brahmaputra basin has higher erosion rates than the world average because of high runoff and the lithology of the basin. We have noticed other literature reporting less erosion rates at other basins (such as Nile) and concluded that this requires further investigation.

\section{Conclusions}

It was concluded that the hydrological and hydraulic reasonably well encapsulate the hydrological and hydraulic processes although the uncertainty in model predictions are rather high. The simulated flood map was found to resemble well the observed one (from satellite imagery) and the probability of detection of inundation was $>70 \%$. The erosion modelling needs further investigation to justify excessive erosion rates in the basin.

\section{References}

[1] Arias-Hidalgo, M., Bhattacharya, B., Mynett, A.E., Van Griensven, A., Experiences in using the TMPA-3B42R satellite data to complement rain gauge measurements in the Ecuadorian coastal foothills. Hydrol. Earth Syst. Sci. 17 (2013) 2905-2915.

[2] Huffman, G. J., Adler, R. F., Bolvin, D. T., Gu, G., Nelkin, E. J., Bowman, K. P., Hong, Y., Stocker, E. F., and Wolff, D. B., The TRMM Multisatellite Precipitation Analysis (TMPA): Quasiglobal, multiyear, combined-sensor precipitation estimates at fine scales, Hydrometeorology, 8 (2007) 38-55.

[3] Sharma, J.R., and Paithankar, Y. (2014). Brahmaputra Basin Report. Ministry of Water Resources, Government of India.

[4] Rodríguez, E., Morris, C.S., Belz, J.E., Chapin, E.C., Martin, J.M., Daffer,W., Hensley, S., An Assessment of the SRTM Topographic Products, Jet Propulsion Laboratory, available online:

https://www2.jpl.nasa.gov/srtm/SRTM_D31639.pdf (last accessed 5/Mar/2018).

[5] Singh, S.K., Erosion and Weathering in the Bramhaputra River System. Large Rivers Geomorphol. Manag., (2007) 375-393. 